\title{
EDITORIAL
}

\section{Pediatric acute myeloid leukemia: international progress and future directions}

\author{
GJL Kaspers ${ }^{1}$, U Creutzig ${ }^{2,3}$ \\ ${ }^{1}$ Department of Pediatrics, Division of Oncology/Hematology, VU university medical center, De Boelelaan, Amsterdam, \\ The Netherlands; ${ }^{2}$ AML committee, International BFM Study Group; and ${ }^{3}$ AML-BFM Group, clo Klinik und Poliklinik für \\ Kinderheilkunde, Pädiatrische Hämatologie/Onkologie, Albert-Schweitzer-Str., Münster, Germany
}

Leukemia (2005) 19, 2025-2029. doi:10.1038/sj.leu.2403958

The prognosis of pediatric acute myeloid leukemia (AML) has improved significantly over the past decades. However, few papers have actually illustrated this improvement, and many articles report on outcome data with relatively short follow-up. Another problem in the literature on pediatric AML is that outcome data of different study groups are difficult to compare, because the patient groups are not defined in a similar way. Differences concern age, inclusion of secondary $\mathrm{AML}$, myeloid leukemia of Down's syndrome and others. Therefore, analogous to the Leukemia issue on pediatric acute lymphoblastic leukemia (ALL), we invited groups from all over the world to describe their experiences on pediatric AML according to specific guidelines. ${ }^{1}$ The platform of the International BFM Study Group and the so-called International Pediatric AML Group enabled coordinating this effort. Manuscripts had to deal with at least two consecutive studies, long-term follow-up on all patients, and with data analysed in a more or less standardised way with the AML-BFM paper as standard. Manuscripts also had to include sub-group analyses and an analysis on a well-defined core group of patients (Table 1). We are pleased that this project succeeded, and that this issue contains 13 original manuscripts from as many groups on pediatric AML. ${ }^{2-14}$ Table 2 summarises the most recently completed and matured studies concerning this core group of patients. Intentionally, also some groups active in less-privileged countries were invited to participate in this project. The treatment of $\mathrm{AML}$ usually requires more facilities than for ALL, and in these countries as well the care for pediatric AML patients should be an important issue. Indeed, the far majority of children with $\mathrm{AML}$ are being diagnosed and treated in such countries.

A potential advantage from this special issue of Leukemia, is the possibility to identify apparently different treatment outcomes of AML subgroups among the study groups, although such differences must be interpreted with caution. This may elicit hypotheses about optimisation of subgroup-directed therapy. The strategies of the study groups have many similarities, such as risk-group directed treatment, the use of the same drugs (cytarabine, anthracycline and etoposide), and blockwise therapy. However, there also are many differences even today, such as the number, design and intensity of blocks given, cumulative doses of the most important drugs (anthracyclines and related drugs, cytarabine and etoposide), indications for allogeneic stem cell transplantation (SCT) and its

Correspondence: Dr GJL Kaspers, Department of Pediatrics, Division Oncology/Hematology, VU university medical center, De Boelelaan 1117, NL-1081 HV Amsterdam, The Netherlands;

Fax: + 3120444 2422; E-mail: gjl.kaspers@vumc.nl

Received 28 July 2005; accepted 19 August 2005 scheduling, the use of cranial irradiation and intrathecal chemotherapy for prophylaxis of CNS relapse, and the use of maintenance treatment. Despite the different strategies, most larger and established groups report more or less similar outcome, as is being summarised in more detail in the next section and in Table 2. Then, quality of life and late effects become more important when comparing strategies. Unfortunately, such information is largely lacking. Overall, a huge improvement in the prognosis of children and adolescents with AML has been accomplished. This is illustrated in this special issue of Leukemia, which also should serve to suggest and identify possibilities for further improvements.

Concerning the international results presented in this issue of Leukemia, all groups report an improved outcome over time. Although not always statistically significant, rates of early death and death in CR declined, complete remission rates increased, relapse rates decreased and therefore, event-free survival (EFS) rates increased. Overall survival rates may also have increased because of more and more successful attempts to cure children with relapsed AML. Improvements can at least in part be explained by increased experience with intensive treatment, better facilities for supportive care and better risk-group stratification with subsequent risk-group adapted treatment. Indeed, the actually applied drugs have not changed much. The concept of applying relatively few but very intensive courses of combination chemotherapy in the first months is likely to explain the improved prognosis as well.

Most frequent events still concern relapses, the far majority occurring in the bone marrow. The cumulative risk of relapse among the different study groups usually is around $30-40 \%$. Central nervous system (CNS) relapses, either isolated or combined, occur in 2-9\% of patients overall. However, CNS relapses contributed to $6-18 \%$ of the total number of relapses.

Table 1 Inclusion and exclusion criteria for the core group of pediatric AML patients, being the subject of similar analyses by all participating groups to allow intergroup comparisons

\begin{tabular}{l} 
Inclusion criteria \\
Age 0-15 years \\
Diagnosis de novo AML \\
FAB M0-M7, unclassifiable AML \\
Exclusion criteria \\
Age 15 years and older \\
AML as secondary malignancy \\
Myelosarcoma without significant BM involvement \\
Myeloid leukemia of Down's syndrome \\
Preceeding Myelodysplastic syndrome \\
Pretreatment with cytostatic drugs (eg, steroids) for more than \\
14 days or intensive treatment \\
\hline
\end{tabular}




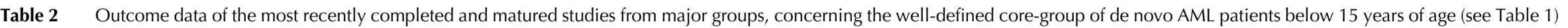

\begin{tabular}{|c|c|c|c|c|c|c|c|c|c|}
\hline $\begin{array}{l}\text { Study, years of enrolment and } \\
\text { reference }\end{array}$ & $\begin{array}{l}\text { Patient } \\
\text { number }\end{array}$ & $\begin{array}{c}\% \text { of } \\
\text { nonresponders }\end{array}$ & $\begin{array}{l}\text { Early death } \\
\text { rate (\%) }\end{array}$ & $\begin{array}{l}\text { CR rate } \\
\text { (\%) }\end{array}$ & $\begin{array}{l}\text { 5-year pEFS } \\
\text { (\%, with s.e.) }\end{array}$ & $\begin{array}{l}\text { 5-year pOS } \\
\text { (\%, with s.e.) }\end{array}$ & $\begin{array}{l}\% \text { death } \\
\text { rate in } C R\end{array}$ & $\begin{array}{l}\text { Cumulative doses of ara-C, } \\
\text { VP16 and anthracyclines }\end{array}$ & $\begin{array}{c}\% \text { of total number of } \\
\text { patients who underwent } \\
\text { (allo-) SCT }\end{array}$ \\
\hline AlEOP92 $(1992-2001)^{10}$ & 160 & 5 & 6 & 89 & $54(4)$ & $60(4)$ & 7 & No strict protocol guidelines & 29 \\
\hline AML-BFM93 (1993-1998) & 427 & 10 & 7 & 83 & $51(3)$ & $58(2)$ & 4 & $\begin{array}{l}41.1 \mathrm{~g} / \mathrm{m}^{2} \\
950 \mathrm{mg} / \mathrm{m}^{2} \\
300-400 \mathrm{mg} / \mathrm{m}^{2}\end{array}$ & 7 \\
\hline CCG2891 (1989-1995) & 750 & 18 & 4 & 78 & $34(3)$ & $47(4)$ & 15 & $\begin{array}{l}14.6 \mathrm{~g} / \mathrm{m}^{2} \\
1100 \mathrm{mg} / \mathrm{m}^{2} \\
180 \mathrm{mg} / \mathrm{m}^{2}\end{array}$ & 25 \\
\hline DCOG-ANLL 92/94 (1992-1998) ${ }^{7}$ & 78 & 8 & 10 & 82 & $42(6)$ & $42(6)$ & 16 & $\begin{array}{l}33.2 \mathrm{~g} / \mathrm{m}^{2} \\
950 \mathrm{mg} / \mathrm{m}^{2} \\
400 \mathrm{mg} / \mathrm{m}^{2}\end{array}$ & 27 \\
\hline EORTC-CLG $58921(1993-2000)^{5}$ & 166 & 13 & 2 & 84 & $48(4)$ & $62(4)$ & 6 & $\begin{array}{l}23.32-29.32 \mathrm{~g} / \mathrm{m}^{2} \\
1350 \mathrm{mg} / \mathrm{m}^{2} \\
380 \mathrm{mg} / \mathrm{m}^{2}\end{array}$ & 20 \\
\hline GATLA-AML90 (1990-1997)² & 179 & 11 & 20 & 70 & $31(4)$ & $41(4)$ & 7 & $\begin{array}{l}41.1 \mathrm{~g} / \mathrm{m}^{2} \\
1450 \mathrm{mg} / \mathrm{m}^{2} \\
300 \mathrm{mg} / \mathrm{m}^{2}\end{array}$ & 3 \\
\hline LAME91 $(1991-1998)^{9}$ & 247 & 5 & 4 & 91 & $48(4)$ & $62(4)$ & 6 & $\begin{array}{l}9.8-13.4 \mathrm{~g} / \mathrm{m}^{2} \\
400 \mathrm{mg} / \mathrm{m}^{2} \\
460 \mathrm{mg} / \mathrm{m}^{2}\end{array}$ & 30 \\
\hline NOPHO-AML93 (1993-2001) & 223 & 5 & 2 & 92 & $50(3)$ & $66(3)$ & 2 & $\begin{array}{l}49.6-61.3 \mathrm{~g} / \mathrm{m}^{2} \\
1600 \mathrm{mg} / \mathrm{m}^{2} \\
300-375 \mathrm{mg} / \mathrm{m}^{2}\end{array}$ & 25 \\
\hline PINDA-92 (1992-1998) ${ }^{11}$ & 151 & 5 & 26 & 68 & 36 & 36 & 4 & $\begin{array}{l}7.64 \mathrm{~g} / \mathrm{m}^{2} \\
450 \mathrm{mg} / \mathrm{m}^{2} \\
350 \mathrm{mg} / \mathrm{m}^{2}\end{array}$ & - \\
\hline POG8821 (1988-1993) & 511 & 19 & 4 & 77 & $32(2)$ & $42(2)$ & 8 & $\begin{array}{l}55.7 \mathrm{~g} / \mathrm{m}^{2} \\
2250 \mathrm{mg} / \mathrm{m}^{2} \\
360 \mathrm{mg} / \mathrm{m}^{2}\end{array}$ & 13 \\
\hline PPLLSG98 (1998-2002) & 104 & 13 & 8 & 80 & $47(5)$ & $50(5)$ & 10 & $\begin{array}{l}7.0-15.1 \mathrm{~g} / \mathrm{m}^{2} \\
450-950 \mathrm{mg} / \mathrm{m}^{2} \\
420-600 \mathrm{mg} / \mathrm{m}^{2}\end{array}$ & Not given, but a minority \\
\hline St. Jude-AML91 (1991-1997) ${ }^{13}$ & 62 & 16 & 3 & 79 & $44(15)$ & $57(11)$ & $?$ & $\begin{array}{l}3.8 \mathrm{~g} / \mathrm{m}^{2} \\
1200 \mathrm{~g} / \mathrm{m}^{2} \\
270 \mathrm{mg} / \mathrm{m}^{2}\end{array}$ & Not given \\
\hline UK-MRC AML10 (1988-1995) & 303 & 3 & 4 & 93 & 49 & 58 & 10 & $\begin{array}{l}10.6 \mathrm{~g} / \mathrm{m}^{2} \\
500-1500 \mathrm{mg} / \mathrm{m}^{2} \\
550 \mathrm{mg} / \mathrm{m}^{2}\end{array}$ & 20 \\
\hline
\end{tabular}

Please note that still the data are not completely comparable for various reasons.

$\mathrm{CR}=$ complete remission; $\mathrm{EFS}=$ event-free survival; $\mathrm{OS}=$ overall survival; ara-C=cytosine arabinoside; VP16=etoposide; $\mathrm{SCT}=$ stem cell transplantation.

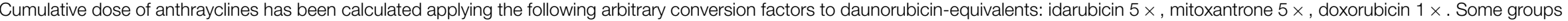
also applied amsacrine (LAME, UK), which has not been included in calculations of total athracyclines exposure. 
Different strategies do not seem to translate in highly different risks for CNS relapse, although formal comparisons are not possible. LAME and POG did not routinely apply intrathecal chemotherapy or cranial irradiation prophylactically in a large proportion of patients, and observed an CNS relapse rate of only 3\% in the LAME 91 Study and 7\% in the POG 8821 Study, respectively. ${ }^{9,12}$ Risk factors for CNS relapse such as CNS-involvement at initial diagnosis are less clear in AML than in ALL. ${ }^{15}$ However, one could argue that efforts are warranted to decrease a cumulative CNS relapse rate of up to $10 \%$, especially keeping in mind the theory that remaining leukemic cells may recede from the CNS to give systemic relapses. The study results presented in this issue and in the literature neither supports or negate cranial irradiation for that purpose since this question has not been addressed in controlled randomised studies (except study AML-BFM 87 with low patient numbers in the randomised groups). However, overall outcome data do not suggest superiority of cranial irradiation, but of course only in the context of the systemic therapy being administered. Similarly, the benefit of maintenance treatment in AML in general, except perhaps for subgroups such as acute promyelocytic leukemia, has not been proven. Two studies randomising with or without maintenance (CCG213 and LAME 91) showed lack of benefit of maintenance treatment and even suggested inferior survival with maintenance. 9,16

In addition, early deaths (mostly disease-related) and toxic deaths in complete remission are frequent events as well, occurring in $2-10 \%$ and in around $5 \%$ (higher in case of frequent SCT) of patients, respectively. Several groups reported a decrease in toxic death rate without changing therapy or even with more intensive therapy. Also, the less favorable prognosis in less-privileged countries is to a significant extent explained by an excess of early and toxic deaths. Obviously experience, centralisation, training and facilities for supportive care are very important, as well as an awareness of these events. ${ }^{17-19}$

An important goal of this project was subgroup analyses. The incidence of the subgroups does not seem to be very different among the study groups, except for acute promyelocytic leukemia (APL, AML FAB type M3) and Down's syndrome. In contrast to ALL, there are currently no identifiable subgroups with a realistic chance of EFS of more than $80-90 \%$, which even seems true for APL and for myeloid leukemia of Down's syndrome. Subgroups that are considered good-risk, especially $\mathrm{t}(8 ; 21)$ and inv $(16)$, have probabilities of 5 -year EFS of $80 \%$ or less. In fact, patients with $\mathrm{t}(8 ; 21)$ do not have such an excellent prognosis as sometimes assumed, with probabilities of 5 -year EFS below $50 \%$ reported by several groups. ${ }^{5,7,9,14}$ Some striking differences in prognosis of subgroups occur, such as for $\mathrm{t}(9 ; 11)$ : 5 -year EFS rates range from 18 to $77 \%,{ }^{8,12}$ for inv(16): 5 -year EFS rates ranging from 41 to $80 \%, 3,14$ and for white blood cell count above $100 \times 10^{9} /$ : 5 -year EFS rates ranging from $17 \%$ to $61 \% .^{5,13}$ Careful comparison of each group's treatment schedules might suggest explanations for these differences in prognosis of subgroups.

What are the future directions and perspectives? Pediatric AML is a complex and life-threatening disease, and optimal facilities are required for its diagnosis, treatment and follow-up. Thus, centralisation of the management of these patients in wellequiped pediatric oncology center is required. The matter of debate is whether young adults should be treated within the setting of pediatric oncology centers, on pediatric protocols. There is data to suggest that indeed the prognosis may be better under such conditions. Besides morphology, and recognizing the limitations in less-privileged countries, facilities nowadays should include immunophenotyping with a broad panel of antibodies, karyotyping and molecular biological techniques such as FISH and PCR. Optimal treatment implies access to all antileukemic and supportive care drugs. Given the intensity of treatment and its side effects, easy access to a pediatric intensive care unit is equally crucial. Finally, pediatric $\mathrm{AML}$ protocols should also include monitoring of quality of life and late effects, which is not routinely being done yet. A well-equipped center also implies well-trained personal. Fortunately, at several meetings and by several organisations educational courses are being offered. All of this is important to accomplish both more efficacious treatment as well as less toxic deaths.

Topics of debate are the need for allogeneic SCT in AML, the required dose of anthracyclines, and the use of low $v s$ high-dose cytarabine. Most if not all groups now seem to agree that lower risk AML subgroups such as myeloid leukemia of Down's syndrome, and patients with $\mathrm{APL}$, inv(16) or $\mathrm{t}(8 ; 21)$ are not candidates for allogeneic SCT. However, the percentage of the other patients considered eligible for allogeneic SCT differs significantly among the groups. An exchange of views and facts has been provided recently. ${ }^{20-22}$ Looking at overall outcome, the frequent use of allogeneic (and autologous) SCT as such does not translate into a better outcome than reported by groups which apply SCT in a minority of patients (Table 2). Dosing of anthracyclines is another interesting subject, further complicated by the use of different drugs than daunorubicin or doxorubicin, such as idarubicin, mitoxantrone and since recently liposomal daunorubicin. A careful look of the cumulative doses of these drugs applied by the different study groups shows that doses above $375 \mathrm{mg} / \mathrm{m}^{2}$ do not necessarily translate into better outcome, while the risk of cardiotoxicity does increase. On the other hand, groups that applied little anthracyclines and/or at a modest intensity during induction chemotherapy seem to report lower probabilities of EFS. However, how much anthracyclines is needed and when and how they should be applied is still unknown, as is the usefulness of individualising these drugs. Regarding cytarabine, different schedules are also being used, including lower and high-doses, with significant differences in cumulative doses (Table 2). High-dose cytarabine is likely to contribute to CNS-prophylaxis, and more importantly, some patients may need higher-dose cytarabine to overcome certain resistance mechanisms. It will be a challenge to individualise cytarabine-dosing in the future.

An important issue that the pediatric community should tackle is a consensus on definitions of diagnosis, response criteria, treatment outcomes and reporting standards for therapeutic trials, specific for the pediatric population. ${ }^{23,24}$ This may seem less important, but is essential for actual collaboration. These definitions should be renewed in this era of very intensive chemotherapy and the fact that often bone marrow regeneration is not awaited before proceeding to another course of chemotherapy or transplantation. Conventional definitions of complete remission, requiring both neutrophil and platelet recovery, are less useful nowadays. ${ }^{23}$ CR definition by morphology alone lacks sensitivity, and minimal residual disease (MRD) monitoring most likely will provide the opportunity to monitor treatment response more precisely. The clinical relevance of MRD monitoring in pediatric AML still has to be established, but it is anticipated that better risk-group stratification can be achieved based on MRD monitoring. ${ }^{25,26}$

Subgroup-identification and subsequent subgroup-specific treatment is a major issue. ${ }^{27}$ Several subgroups have already been well-defined, as can also be seen in the papers in this Leukemia issue. At least some groups observed that patients with myeloid leukemia of Down's syndrome, APL and inv(16) do 
relatively well, although not perfect yet. Similarly, some patients do worse, such as those with complex karyotypic abnormalities and a poor initial response to chemotherapy. However, we are far from a black-and-white discrimination, and therefore novel subgroups should be identified. Since usually these groups are small, this is another area in which collaboration is very useful. Several collaborations in pediatric ALL and the recent intergroup effort to analyse AML patients with monosomy 7 and $7 q-$ is a good example that this can be done successfully (Hasle et al. Blood 2004; 104: abstract). Molecular biological techniques have already identified subgroups, such as patients with activating receptor kinase mutations, ${ }^{28}$ and patients with specific gene expression profiles. ${ }^{29}$ However, overall survival will probably only improve to a significant extent if we can introduce subgroup-specific treatment. Exciting innovative therapies are emerging, such as monoclonal antibody mediated treatment and tyrosine kinase inhibitors. ${ }^{30}$ In order to demonstrate the value of new therapies an international collaboration is a prerequisite, because of the small numbers and the already high survival probability of about $60 \%$ nowadays. Indeed, the participation of more than 10 groups worldwide in an ongoing intergroup randomised phase III study in relapsed AML that now accrued more than 300 children illustrates that this is feasible.

Of course, the typical example in AML illustrating that subgroup-directed treatment can be very successful is the treatment of APL with all-trans retinoic acid and more recently with arsenic trioxide, in combination with chemotherapy. ${ }^{31}$ Why could we not develop similarly successful targeted treatment for other subgroups? There is at least one disadvantage when developing subgroup-directed therapy. The classical randomised trials in larger groups of patients will become impossible, at least in children in whom this disease is relatively rare. This problem is nicely illustrated by the limited number of randomised trials in pediatric $\mathrm{AML}$, even without significant subgroup-directed therapy. Solving this problem by participating in adult-driven trials seems potentially disadvantageous. Children are not small adults, because they have different pharmacokinetics, different toxicity profiles and because the incidence of specific subtypes of AML (eg, Flt3-internal tandem duplications) differs from that in adults. As it is doubtful that results mainly obtained in adult populations can be extrapolated to the pediatric population, more extensive intergroup collaborations in pediatric AML are warranted. Adding up the annual numbers of newly diagnosed pediatric AML among the groups that participated in this 'spotlights' certainly indicates that there are enough new cases potentially. Many successful trials in children and adolescents with AML have been completed by several national groups, as illustrated in this special issue of Leukemia. International collaboration focussed on more targeted and tailored therapy, aiming at the cure of more children with AML with less side-effects, is the next challenge.

\section{Acknowledgements}

We thank all groups and their co-workers for participating in this project. We also thank the members of the AML committee of the International BFM Study Group, the International BFM Group Study Group itself (chaired by M Schrappe) and the participants in the International Pediatric AML Group for supporting this project. Finally, we thank Leukemia for the opportunity to publish this special issue on pediatric AML. Especially Nicole Muller-Berat Killmann, Julia Chapman and Ching-Hon Pui played important roles.

\section{References}

1 Schrappe M, Camitta B, Pui CH, Eden T, Gaynon P, Gustafsson G et al. Long-term results of large prospective trials in childhood acute lymphoblastic leukemia. Leukemia 2000; 14: 2193-2194.

2 Armendariz H, Fernandez Barbieri MA, Freigeiro D, Lastiri F, Felice MS, Dibar E. Treatment strategy and and long-term results in pediatric patients treated in two consecutive AML-GATLA-trials. Leukemia 2005, in press.

3 Creutzig U, Zimmermann M, Ritter J, Reinhardt D, Hermann J, Henze G, et al, for the AML-BFM Study Group. Treatment strategies and long-term results in pediatric patients treated in four consecutive AML-BFM trials. Leukemia 2005, in press.

4 Dluzniewska A, Balwierz W, Armata J, Balcerska A, Chybicka A, Kowalczyk J, et al, for the Polish Pediatric Leukemia/Lymphoma Study Group (PPLSG). Twenty years of Polish experience with three consecutive protocols for treatment of childhood acute myelogenous leukemia. Leukemia 2005, in press.

5 Entz-Werle N, Suciu S, Van Der Werff ten Bosch J, Vilmer E, Bertrand Y, Benit Y, et al, on behalf of EORTC Children Leukemia Group (CLG). Results of 58872 and 58921 trials in acute myeloblastic leukemia (AML) and relative value of chemotherapy vs allogeneic bone marrow transplantation (alloBMT) in $1 \mathrm{st}$ complete remission: the EORTC Children Leukemia Group report. Leukemia 2005, in press.

6 Gibson BES, Wheatley K, Hann IM, Stevens RF, Webb D, Hills RK, et al, for the United Kingdom Childhood Leukaemia Working Party and the Dutch Childhood Oncology Group. Treatment Strategy and Long-term results in paediatric patients treated in consecutive UK AML Trials. Leukemia 2005, In press.

7 Kardos G, Zwaan CM, Kaspers GJL, De Graaf SSN, De Bont ESJM, Postma A et al. Treatment strategy and results in children treated on three Dutch Childhood Oncology Group acute myeloid leukemia (AML) trials. Leukemia 2005, in press.

8 Lie SO, Abrahamsson J, Clausen N, Forestier E, Hasle H, Hovi L, et al, on behalf of the Nordic Society of Pediatric Hematology and Oncology (NOPHO). Long-term results in children with AML: NOPHO-AML Study Group - Report of three consecutive trials. Leukemia 2005, in press.

9 Perel Y, Auvrignon A, Leblanc T, Michel G, Reguerre Y, Vannier J$\mathrm{P}$, et al, for the Group LAME of the Societe Francaise des Cancers de IÉnfant (SFCE), France. Treatment of childhood acute myeloblastic leukemia. Dose intensification improves outcome and maintenance therapy is of no benefit. Multicenter studies of the French LAME (Leucémie Aiguë Myéloblastique Enfant) Cooperative Group. Leukemia 2005, in press.

10 Pession A, Rondelli R, Basso G, Rizzari C, Testi AM, Fagioli F, et al, on behalf of the AML Strategy \& Study Committee of the Associazione Italiana Ematologia Oncologia Pediatrica (AIEOP). Treatment and long-term results in children with acute myeloid leukaemia (AML) treated according to the AIEOP AML Protocols. Leukemia 2005, in press.

11 Quintana J, Advis P, Becker A, Beresi V, Campbell M, García H, et al, for the Programa Infantil de Drogas Antineoplásicas de Chile (PINDA) and Vinés EF. Acute myelogenous leukemia in Chile. Mature results from PINDA protocols 87 and 92. Leukemia 2005, in press.

12 Ravindranath Y, Chang M, Steuber CP, Becton D, Dahl G, Civin C, et al, for the Pediatric Oncology Group. Pediatric Oncology Group (POG) studies of Acute Myeloid Leukemia (AML): a review of four consecutive childhood AML trials conducted between 1981 and 2000. Leukemia 2005, in press.

13 Ribeiro RC, Razzouk BI, Pounds S, Hijiya N, Pui C-H, Rubnitz JE. Successive clinical trials for childhood acute myeloid leukemia at St Jude Children's Research Hospital, 1980 through 2000. Leukemia 2005, in press.

14 Smith FO, Alonzo TA, Gerbnig RB, Woods WG, Arceci RJ, for the Children's Cancer Group. Long-term results of children with acute myeloid leukaemia: A report of three consecutive phase III trials by the Children's Cancer group: CCG251, CCG 213 and CCG 2891. Leukemia 2005, in press.

15 Abbott BL, Rubnitz JE, Tong X, Srivastava DK, Pui CH, Ribeiro RC et al. Clinical significance of central nervous system involvement at diagnosis of pediatric acute myeloid leukemia: a single institution's experience. Leukemia 2003; 17: 2090-2096. 
16 Wells RJ, Woods WG, Buckley JD, Odom LF, Benjamin D, Bernstein I et al. Treatment of newly diagnosed children and adolescents with acute myeloid leukaemia: a Childrens Cancer Group Study. J Clin Oncol 1994; 12: 2367-2377.

17 Creutzig U, Zimmermann M, Reinhardt D, Dworzak M, Stary J, Lehrnbecher T. Early deaths and treatment-related mortality in children undergoing therapy for acute myeloid leukemia: analysis of the multicenter clinical trials AML-BFM 93 and AML-BFM 98. J Clin Oncol 2004; 22: 4384-4393.

18 Lehrnbecher T, Varwig D, Kaiser J, Reinhardt D, Klingebiel T, Creutzig U. Infectious complications in pediatric acute myeloid leukemia: analysis of the prospective multi-institutional clinical trial AML-BFM 93. Leukemia 2004; 18: 72-77.

19 Slats AM, Egeler RM, Van Der Does-van den Berg A, Korbijn C, Hählen K, Kamps WA et al. Causes of death other than progressive leukemia in childhood acute lymphoblastic (ALL) and myeloid leukemia (AML): the Dutch Childhood Oncology Group experience. Leukemia 2005; 19: 537-544.

20 Creutzig U, Reinhardt D. Current controversies: which patients with acute myeloid leukaemia should receive a bone marrow transplantation? A European view. Br J Haematol 2002; 118: 365-377.

21 Chen AR, Alonzo TA, Woods WG, Arceci RJ. Current controversies: which patients with acute myeloid leukaemia should receive a bone marrow transplantation? - An American view. Br Haemato 2002; 118: 378-384.

22 Wheatley K. Current controversies: which patients with acute myeloid leukemia should receive a bone marrow transplantation? A statistician's view. Br J Haematol 2002; 118: 351-356.

23 Creutzig U, Kaspers GJL. Revised recommendations of the International Working Group for diagnosis, standardization of response criteria, treatment outcomes, and reporting standards for therapeutic trials in acute myeloid leukemia. J Clin Oncol 2004; 22: $3432-3433$

24 Hasle H, Niemeyer CM, Chessells JM, Baumann I, Bennett JM, Kerndrup $\mathrm{G}$ et al. A pediatric approach to the WHO classification of myelodysplastic and myeloproliferative diseases. Leukemia 2003; 17: 277-282.

25 Reinhardt D, Langebrake C, Creutzig U, Vormoor J, Brune C, Thorwesten $\mathrm{M}$ et al. Minimal residual disease in acute myeloid leukemia in children - standardization and evaluation of immunohenotyping in the AML-BFM-98 study. Klin Pädiatr 2002; 214: 179-187.

26 Sievers EL, Lang BJ, Alonzo TA, Gerbing RB, Bernstein ID, Smith FO et al. Immunophenotypic evidence of leukemia after induction therapy predicts relapse: results from retrospective Children's Cancer Group study of 252 patients with acute myeloid leukemia. Blood 2003; 101: 3398-3406.

27 Zwaan CM, Kaspers GJL. Possibilities for tailored and targeted therapy in childhood acute myeloid leukemia. $\mathrm{Br} J$ Haematol 2004; 127: 264-279.

28 Goemans BF, Zwaan C, Miller M, Zimmermann M, Harlow A, Meshinchi $S$ et al. Mutations in KIT and RAS are frequent events in pediatric core-binding factor acute myeloid leukemia. Leukemia 2005; 19: 1536-1542.

29 Lacayo NJ, Meshinchi S, Kinnunen P, Yu R, Wang Y, Stuber CM et al. Gene expression profiles at diagnosis in de novo childhood AML patients identify FLT3 mutations with good clinical outcomes. Blood 2004; 104: 2646-2654.

30 Appelbaum FR. New targets for therapy in acute myeloid leukemia. Leukemia 2003; 17: 492-495.

31 Ravindranath Y, Gregory J, Feusner J. Treatment of acute promyelocytic leukemia in children: arsenic or ATRA. Leukemia 2004; 18: 1576-1577. 